\title{
FUNKCJA KRĄŻKÓW GLINIANYCH LUDNOŚCI KULTURY ŁUŻYCKIEJ W ŚWIETLE NOWYCH ZNALEZISK Z WIELKOPOLSKI
}

\section{FUNCTION OF THE LUSATIAN CLAY DISCS IN THE LIGHT OF NEW FINDS FROM WIELKOPOLSKA}

\author{
Justyna Żychlińska \\ Katedra Archeologii i Cywilizacji Starożytnych \\ Instytut Historii i Stosunków Międzynarodowych, Uniwersytet Kazimierza Wielkiego \\ ul. Księcia Józefa Poniatowskiego 12, 85-671 Bydgoszcz \\ justyna.zychlinska@ukw.edu.pl
}

\begin{abstract}
Although the collection of "Lusatian" clay discs is quite significant, not much attention has been paid so far to their interpretation. The discs might have been used for various purposes in "Lusatian" society, e.g. as toys for children, or the Sun cult objects. They might have also played strictly utilitarian role of spindle whorls, polishing stones in pottery workshops, or miniature pads used in casting process. It would be difficult to accept any of the hypotheses exclusively, as it seems that the discs might have had various functions depending, among others, on the socio-economic context in which they appeared.
\end{abstract}

KEY WORDS: clay discs, Lusatian culture.

Obszar wschodniej oraz środkowej Wielkopolski w końcu lat 90. XX w. poddany był szerokopłaszczyznowym badaniom związanym z planowaną inwestycją budowy autostrady A2. W wyniku tych prac odkryto wiele stanowisk archeologicznych, na których zarejestrowano niezwykle interesujący materiał zabytkowy. Jednymi z nich były stanowiska w Beznazwie, pow. Turek, i Krerowie, pow. Poznań. Na nich to właśnie zostały znalezione wspomniane w tytule krążki gliniane.

$\mathrm{Z}$ pierwszej osady pochodzi jeden egzemplarz (ryc. 1:1), z drugiej dwa dalsze (ryc. 1:2,3). Wszystkie zostały wykonane z przydennych partii brzuśców naczyń o średnicach ok. $5 \mathrm{~cm}$. Krążek z Beznazwy został odkryty w warstwie kulturowej datowanej w szerokich ramach funkcjonowania osady ludności kultury łużyckiej, czyli od drugiej połowy V okresu epoki brązu (dalej EB) do okresu halsztackiego 
(dalej Ha) D. Natomiast egzemplarze z Krerowa odsłonięto w nieruchomych obiektach kulturowych (ob. 113 - jama o charakterze mieszkalnym i ob. 358 - jama o nieokreślonej funkcji osadniczej), z których pierwszy datowany był na przełom $\mathrm{V}$ EB i Ha C, natomiast drugi na Ha D.
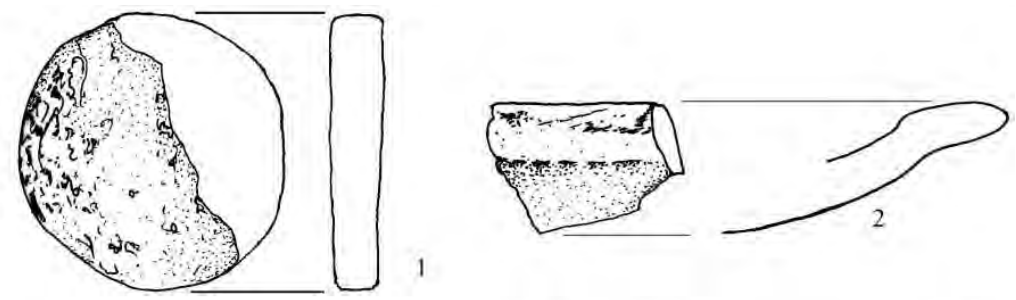

\section{,}
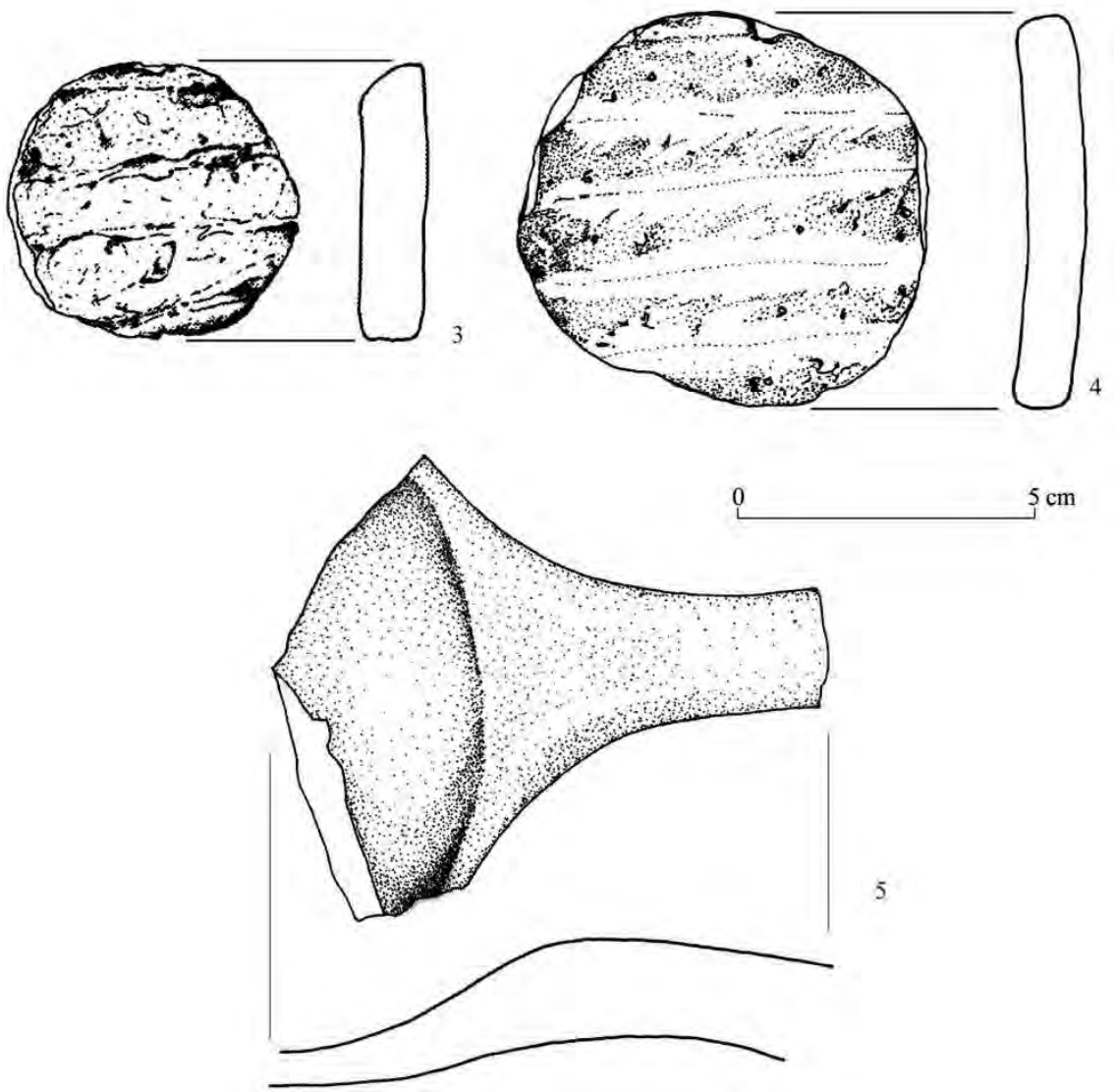

Ryc. 1. Krążki ceramiczne i łyżki ceramiczne z osad ludności kultury łużyckiej: 1, 2 - Beznazwa, pow. Turek, woj. wielkopolskie; 3-5-Krerowo, pow. Poznań, woj. wielkopolskie

Fig. 1. Clay discs and spoons from the Lusatian settlements: 1, 2 - Beznazwa, Turek county, Wielkopolskie province; 3-5-Krerowo, Poznań county, Wielkopolskie province 
Krążki gliniane wykonane z fragmentów naczyń, z części przydennych lub środkowych brzuśców są rzadko spotykane na stanowiskach datowanych na I EB (Masojć, Paruzel 2006, ryc. 9:6). Równie rzadko występują na stanowiskach kultury pomorskiej lub grobów kloszowych (Muzolf 2002, s. 241, ryc. 127:10). W nieco większej liczbie spotyka się je na stanowiskach kultury przeworskiej, datowanych na okres przedrzymski i okres wpływów rzymskich ${ }^{1}$.

W środowisku kultury łużyckiej krążki wykonane z fragmentów naczyń ceramicznych, z wypłaszczonych części przydennych lub środkowych brzuśców, z fragmentów placków krążkowatych (tj. talerzy), czasami z den naczyń, poza bardzo licznym zespołem z grodu w Biskupinie, pow. żniński, skąd pochodzi ponad 100 egzemplarzy (Kołosówna 1950, s. 231), znane są z kilku stanowisk, głównie osadniczych (Bukowski 1960, s. 211-212, tab. XLVII:22-28; Byrska i in. 2006, ryc. 14:3,4; Dąbrowski 1997, s. 41, ryc. 11:e; Dąbrowski, Mogielnicka-Urban 1981b, tab. XII:3; Dobrakowski, Domańska, Lodowski, Noworyta, Romanow 2001, ryc. 20:9; Fogel 1985, s. 73, ryc. 24:2,3; Gediga 1976a, s. 49-50, 152-153; Głogowski, Szamałek, Ignaczak 2004, s. 315, ryc. 41:4; Harding, Ostoja-Zagórski, Palmer, Rackham 2004, s. 60, 250; Krzyszowski 2008, s. 62-63, ryc. 8:5; Malinowski 2006, s. 135, ryc. 104:5,6; Mierzwiński 2003, s. 155, 158, ryc. 56:1-16). Nieliczne zostały odkryte na cmentarzyskach (Kaczmarek 2002, s. 116, ryc. 47:2, zest. 31 - 4 egz.; Marcinkian 1972, s. 294, tab. LXXVII:11).

Zbiór biskupiński autorka tego opracowania podzieliła na egzemplarze wykonane ze skorup z oszlifowanym brzegiem, z obtłuczonym brzegiem, z otworkami (Kołosówna 1950, ryc. 6, 9) lub bez otworków i na egzemplarze powstałe z podkładek, ulepione z gliny, z otworkami lub bez otworków. Najczęściej są one okrągłe, zdarzają się jednak kwadratowe (Kołosówna 1950, ryc. 5) i prostokątne (Kołosówna 1950, ryc. 8).

Poza egzemplarzem z grobu datowanego na przełom III i IV EB (Marcinkian 1972, s. 294) chronologia krążków „łużyckich” zamyka się w ramach od przełomu V EB i Ha C do Ha D (przełom V EB i Ha C - Byrska i in. 2006, s. 500; Dąbrowski, Mogielnicka-Urban 1981a, s. 225; Fogel 1985, s. 92; Ha C - Dobrakowski, Domańska, Lodowski, Noworyta, Romanow 2001, s. 138, i Ha D - Bukowski 1960; Harding, Ostoja-Zagórski, Palmer, Reckham 2004, s. 250; Głogowski, Szamałek, Ignaczak 2004, s. 319-320; Kołosówna 1950, s. 238; Krzyszowski 2008, s. 67; Malinowski 2006, s. 148).

Nie można niestety wskazać obszarów ich wyraźnej koncentracji. Poza Kujawami, gdzie odnotowano największą liczbę krążków, choć na zaledwie dwóch sta-

\footnotetext{
${ }^{1}$ Prochnowicz 1999, s. 307. Autor wymienia 34 egzemplarze. Nowsze odkrycia pochodzą np. z Podłęża, pow. Wieliczka (Dzięgielewska, Dzięgielewski, Nowak, Szczerba 2006, ryc. 18 [kolorowa wkładka]), z Nowej Wsi, pow. Bolesławiec (Pazda, Konczewska, Konczewski 2006, ryc. 12:g), czy z Wierzchowic, pow. Jawor (Kendelewicz 2006, ryc. 6:9, 10).
} 
nowiskach (Kołosówna 1950; Głogowski, Szamałek, Ignaczak 2004), spotyka się je w Polsce północno-wschodniej (cztery stanowiska - Dąbrowski 1997; Dąbrowski, Mogielnicka-Urban 1981b), na Dolnym Śląsku (Dobrakowski, Domańska, Lodowski, Noworyta, Romanow 2001), w Małopolsce (Byrska i in. 2006), jak również w Wielkopolsce (siedem stanowisk - Fogel 1985; Kaczmarek 2002; Krzyszowski 2008).

Mimo że zbiór krążków „łużyckich” jest dość znaczny, do tej pory nie poświęcono mu zbyt wielkiej uwagi (Gediga 1976b; Kołosówna 1950; Wieczorowski 1938). Zdecydowanie większe zainteresowanie odnośnie do tej kwestii okazali badacze okresu przedrzymskiego i rzymskiego (Cofta-Broniewska 1979, s. 180; Dąbrowska 1988, s. 130; Kołacz 1995, s. 53; Muzolf 1999, s. 46, ryc. 37:3; Woźniak 1990).

Jeśli chodzi o funkcję utylitarną krążków ceramicznych, to niektórzy badacze okresu rzymskiego są zdania, że egzemplarze z otworkiem były używane jako przęśliki (Jacobi 1974, s. 60; Meduna 1980, s. 129; Woźniak 1980, s. 254-255), natomiast te bez otworów lub ze śladami nawiercania uznają za ich prefabrykaty (Hadaczek 1914, s. 59). Spotkać można też opozycyjne stanowisko, które wyraźnie wyklucza interpretowanie ich jako przęśliki, z powodu zbyt małych otworów (Czerska 1972, s. 46- 47). Podobnego zdania jest autorka opracowania zbioru biskupińskiego, która poza uwagami dotyczącymi zbyt małej średnicy otworów (1,5-2,5 mm) podkreśla także, iż niektóre z nich miały przekrój klepsydrowaty, co ewidentnie wykluczałoby używanie ich jako przęślików (Kołosówna 1950, s. 232).

Krążki bez otworów uważa się niekiedy za gładziki (Bender 1980, s. 374-374; Kołacz 1995, s. 53), choć trzeba sobie zdawać sprawę, że ówcześni ludzie dysponowali dużymi możliwościami uzyskania narzędzi mogących pełnić funkcję gładzików ${ }^{2}$.

Można też spotkać hipotezę, według której krążki te miały być miniaturowymi prawidłami odlewniczymi (Mierzwiński 2003, s. 158).

Poza funkcją utylitarną interesującą koncepcję dotyczącą ich zastosowania podaje Zoja Kołosówna, która uważa je za dziecięce zabawki ${ }^{3}$, pisząc, że „małe skupienia, jakie w kilku miejscach tworzą, są dowodem zabawy, w jakiej w tym miejscu brało udział więcej dzieci” (Kołosówna 1950, s. 233). Krążki z oszlifowanymi brzegami są dla niej wytworem dorosłych, a te $\mathrm{z}$ brzegami obthuczonymi dziecięcym naśladownictwem (Kołosówna 1950, s. 233). Dziurki natomiast thumaczy nawlekaniem je na sznur lub rzemień, co umożliwiało ich kręcenie (Kołosówna 1950, s. 233) ${ }^{4}$. Podobnie funkcję krążków jako zabawek dziecięcych thumaczą Tadeusz

\footnotetext{
${ }^{2}$ Takimi jak chociażby niewielkie obłe kamyki, tzw. serki czy chlebki, fragmenty żeber zwierzęcych, jak też muszle, łupiny, skorupy owoców (por. Mogielnicka-Urban 1984, s. 23-24).

${ }^{3}$ Odpowiednik dzisiejszej gry w kulki, gry „Pchełki” lub „Pokemony”?

${ }^{4}$ Być może chodzi tutaj o uzyskanie większej odległości podczas rzutów.
} 
Wieczorkowski (1938, s. 37), Vladimir Podborský (1965, s. 56), Dietmar-Wilfried Buck (1979, s. 131) czy Andrzej Krzyszowski (2008, s. 62-63).

Niektórzy badacze przypisują omawianym krążkom znaczenie magiczne, wiążąc je z kultem Słońca-Ognia (Cehak-Hołubowiczówna 1959; Czerska 1972, s. 64-65), Księżyca (Cofta-Broniewska 1979, s. 180) lub uznając za symbol słońca lub księżyca (Gediga 1976b, s. 107). Dla niektórych znalezisk z okresu przedrzymskiego i rzymskiego główną przesłanką do przypisywania im znaczenia magicznego stał się kontekst, w jakim je te odkryto - w pobliżu lub w samym wypełnisku obiektów interpretowanych jako kultowe (Makiewicz, Prinke 1980).

Podsumowując nasze rozważania na temat funkcji krążków występujących w pradziejach na ziemiach polskich, należy podkreślić, że w przypadku egzemplarzy odkrywanych na stanowiskach ludności kultury łużyckiej ustosunkowanie się do którejkolwiek hipotezy jest trudne. Nie można wykluczyć, że przeznaczenie owych przedmiotów mogło być wielorakie, w zależności m.in. od kontekstu społeczno-gospodarczego, w jakim były używane.

Wydaje się jednak słuszne odrzucenie ich przeznaczenia jako przęślików czy gładzików z powodów podanych wyżej.

Odnośnie do funkcji kultowej czy magicznej wyraźnie należy podkreślić, że w środowisku „łużyckim” tylko nieliczne krążki zostały odkryte na cmentarzyskach, a więc w sakralnych, uświęconych miejscach, lub obiektach uznanych za kultowe (Cehak-Hołubowiczowa $1959^{5}$ ), natomiast większość z nich została ujawniona na stanowiskach osadniczych $^{6}$, zarówno w obiektach kulturowych, także o charakterze mieszkalnym ${ }^{7}$, jak i w warstwie kulturowej ${ }^{8}$. Na osadach tych nie zarejestrowano jakiegokolwiek obiektu, który mógłby być uznany za kultowy w myśl istniejących w literaturze przedmiotu kryteriów wydzielających takowe (Makiewicz, Prinke 1980 i tam dalsza literatura). Podkreślić także należy, że spośród krążków, o których wspomniałam wyżej, sporadycznie zdarzają się egzemplarze, które zostały wykonane $\mathrm{z}$ ornamentowanych partii naczyń ${ }^{9}$. Ponadto symbole i znaki, które wiązane są z kultem solarnym, to najczęściej dyski, tarcze, koła koncentryczne, spirale, krzyże, swastyki czy trykwetry. Przyjmowanie kultowej funkcji krążków, bazujące głównie

\footnotetext{
${ }^{5}$ Tak wczesna chronologia, tj. odnosząca się do czasów funkcjonowania kultury łużyckiej, obiektów na Ślęży, Raduni i Wieżycy, jest obecnie poddana szerokiej krytyce (por. Słupecki 1992).

${ }^{6} \mathrm{~W}$ nieznacznej przewadze są to stanowiska grodowe, na których zresztą odkrywano większą liczbę krążków (zob. przyp. 5).

${ }^{7}$ Zob. egzemplarze z Krerowa.

${ }^{8}$ Np. krążek z Beznazwy.

${ }^{9}$ Egzemplarz z Kamionki Nadbużnej ,zdobiony” jest promienistmi liniami rytymi (Dąbrowski 1997, ryc. 11:e), a jeden z krążków z Biskupina: trzema promienistymi liniami rytymi rozdzielonymi otworkiem i dołkami (Kołosówna, 1950, ryc. 4). Zdecydowana większość krążków ceramicznych została wykonana z naczyń o powierzchni chropowaconej, szorstkiej, czasami z odciskami dołkowopaznokciowymi.
} 
na ich okrągłym kształcie, jest poważnym błędem, zwłaszcza że z tą koncepcją wyraźnie „kłócą się” krążki kwadratowe czy prostokątne.

Niemałych problemów przysparza weryfikacja hipotezy, według której krążki należy uznać za zabawki, ponieważ nie ma w literaturze przedmiotu wyraźnych zasad ich wydzielania. Czym jest zabawka, wie przecież każdy - to przedmiot służący do zabawy najczęściej dzieciom, ale także dorosłym, a dziś także i zwierzętom. W literaturze przedmiotu od dłuższego czasu panuje pogląd, że większość przedmiotów miniaturowych, które są czasami wierną kopią wytworów funkcjonujących w pradziejowych gospodarstwach (także i takie, które dziś są nierozerwalnie związane $\mathrm{z}$ dziecięcym światem, jak np. grzechotki czy inne umieszczane w kategorii tzw. plastyki figuralnej, np. figurki ornitomorficzne czy zoomorficzne, plastyczne wyobrażenia butów, rogi do picia i wiele innych), jest związana ze sferą wierzeniową (np. Gediga 1976b, 1979, s. 320-342; Ostoja-Zagórski 1996; Gediga, Piotrowska 2000). Nie można w tym miejscu nie wspomnieć, iż nieliczne krążki ceramiczne (5 egzemplarzy) były darami grobowymi, jednakże brak analiz antropologicznych kości ludzkich pochodzących z tych zespołów nie pozwala określić, czy były one darami dla dzieci.

$\mathrm{Na}$ zakończenie przyjrzyjmy się ostatniej z przedstawionych wyżej hipotez, w myśl której krążki ceramiczne wykorzystywano jako miniaturowe podkładki odlewnicze. Andrzej Mierzwiński analizując w procesie metalurgicznym stosowanie metody odlewniczej „na wosk tracony” z użyciem form niszczejących, zwraca uwagę na wykorzystywanie w niej placków krążkowych (tj. talerzy) i krążków wykonanych z fragmentów zużytych placków lub wypłaszczonych partii naczyń - pierwsze pełniłyby funkcję podkładek (Mierzwiński 2003, s. 146 i n.), a drugie: prawideł (Mierzwiński 2003, s. 160). Biorąc pod uwagę cechy morfologiczne niektórych elementów oprzyrządowania, jak np. lejki, a zwłaszcza ich wachlarzowaty obrys w partii brzegowej, badacz ten rekonstruuje graficznie budowę urządzenia wlewowego i jego sposób umocowania na kolistej podkładce, która rozwiązywała problem swobodnego operowania formą odlewniczą, dając możliwość zwiększenia potencjału wytwórczego i zapewniając jednocześnie minimum bezpieczeństwa dłoniom (Mierzwiński 2003, s. 148-149, 152-153). Parametry technologiczne masy garncarskiej oraz obecność ornamentu palcowego, zabiegów schropowacania powierzchni placków krążkowych ${ }^{10}$ thumaczy on względami technologicznymi, które pozwalały na łagodzenie szoku termicznego podczas wlewania płynnego metalu do formy (Mierzwiński 2003, s. 157).

Według A. Mierzwińskiego wyraźna jest zbieżność zarówno czasowa, jak i terytorialna występowania niszczejących form odlewniczych i innych śladów aktywności metalurgicznej (np. lejki, tygle, łyżki odlewnicze) oraz placków krążko-

\footnotetext{
${ }^{10}$ Krążki wykonywane były najczęściej z fragmentów naczyń chropowaconych, szorstkich, czasem zdobionych ornamentem palcowym.
} 
wych $^{11}$. Placki krążkowe i krążki ceramiczne stanowią zatem rozszerzenie bazy narzędziowej związanej z procesem metalurgicznym, będąc jednocześnie dowodem na powszechne praktykowanie odlewnictwa brązu na terenach dorzecza Odry i Wisły (Mierzwiński 2003, s. 148). Nasze znaleziska z Beznazwy i Krerowa doskonale wpisują się w tę hipotezę, zwłaszcza że zarówno na jednym, jak i drugim odkryto fragmenty łyżek związanych z procesem metalurgicznym (ryc. 1:2, 5). Trzeba też dodać, że tak czysto utylitarne określenie funkcji krążków nie przekreśla ich aspektu symbolicznego. Proces metalurgiczny związany jest przecież z operowaniem ogniem, a ten $\mathrm{w}$ wielu prehistorycznych i starożytnych kulturach traktowany był jako ziemski przedstawiciel Słońca - symbolu nieskończoności, źródła energii i mocy życiowej. W tym kontekście akt metalurgiczny ma niewątpliwie znacznie magiczne.

Powyższy przegląd opinii na temat funkcji i znaczenia glinianych krążków w kulturze łużyckiej, a także innych kulturach archeologicznych, skłania do stwierdzenia, że trudno jednoznacznie ocenić ich przeznaczenie. Jak już wspomniałam, ich wykorzystywanie mogło być jednak wielorakie, wynikające z kontekstu społecznego, w jakim funkcjonowały, dlatego nie można podejmować jakichkolwiek prób generalizowania ich zastosowania.

\section{BIBLIOGRAFIA}

Bender W.

1980 Kompleks osadniczy w miejscowości Wólka Łasiecka na tle osadnictwa dorzecza Bzury. Archeologia Polski, 25(2), s. 335-392.

Buck D.-W.

1979 Die Billendorfer Gruppe (Teil II-Text). Veröfentlichungen des Museums für Ur- unf Frühgeschichte Potsdam, 13, Berlin.

Bukowski Z.

1960 Łużyckie osiedle obronne w Sobiejuchach, pow. Żnin. Wiadomości Archeologiczne, 26(3-4), s. 194.

Byrska M., Fraś J., Matoga A., Pieróg I., Przybyła M., Stefański D.

2006 Wstępne wyniki ratowniczych badań archeologicznych na wielokulturowych stanowiskach 8, 11, 12, 14, 15 oraz 20 w Krakowie-Bieżanowie, woj. Małopolskie. W: Z. Bukowski, M. Gerlach, Raport 2003-2004, t. 2, Wstępne wyniki konserwatorskich badań archeologicznych $w$ strefie budowy autostrad w Polsce za lata 2003-2004. Warszawa: Ośrodek Ochrony Dziedzictwa Archeologicznego, s. 491-508.

Cehak-Hołubowiczowa $\mathrm{H}$.

1959 Kamienne kręgi kultowe na Raduni i Ślęży. Archeologia Polski, 3, s. 51-100.

Cofta-Broniewska A.

1979 Grupa kruszańska kultury przeworskiej. Ze studiów nad rozwojem regionalizmu społeczeństw Kujaw. Poznań: Wydawnictwo Naukowe Uniwersytetu im. Adama Mickiewicza w Poznaniu.

\footnotetext{
${ }^{11}$ Schyłek V EB i wczesna epoka żelaza w strefie środkowoeuropejskiej (Mierzwiński 2003, s. 145-146).
} 
Czerska B.

1972 Celtycki ośrodek kultury w Sułkowie w powiecie Głubczyce. Studia Archeologiczne, 5, Wrocław, s. 3-79.

Dąbrowska T.

1988 Wczesne fazy kultury przeworskiej. Chronologia - zasięg - powiazania. Warszawa: Państwowe Wydawnictwo Naukowe.

Dąbrowski J.

1997 Epoka brazu w pótnocno-wschodniej Polsce. Białystok: Białostockie Towarzystwo Naukowe.

Dąbrowski J., Mogielnicka-Urban M.

1981a Analiza materiałów kultury łużyckiej ze stanowisk 1-5 w Worytach. W: J. Dąbrowski (red.), Woryty. Studium archeologiczno-przyrodnicze zespołu osadniczego kultury tużyckiej (s. 203-228). Wrocław: Zakład Narodowy im. Ossolińskich, Wydawnictwo Polskiej Akademii Nauk.

Dąbrowski J., Mogielnicka-Urban M.

1981b Materiały kultury łużyckiej z badań na stanowiskach 2-5 w Worytach w latach 19691974. W: J. Dąbrowski (red.), Woryty. Studium archeologiczno-przyrodnicze zespolu osadniczego kultury tużyckiej (s. 87-169). Wrocław: Zakład Narodowy im. Ossolińskich, Wydawnictwo Polskiej Akademii Nauk.

Dobrakowski M., Domańska J., Lodowski J., Noworyta E., Romanow K.

2001 Wstępne sprawozdanie $\mathrm{z}$ archeologicznych badań ratowniczych na stanowiskach: Polwica 4 i 5 oraz Skrzypnik 8, gm. Domaniów, woj. dolnośląskie, przy budowie autostrady A-4. W: K. Kraśniewska (red.), Raport 96-99. Wstępne wyniki konserwatorskich badań archeologicznych $w$ strefie budowy autostrad w Polsce za lata 1996-1999. Warszawa: Ośrodek Ratowniczych Badań Archeologicznych, s. 130-185.

Dzięgielewska M., Dzięgielewski K., Nowak M., Szczerba R.

2006 Osada grupy wyciącko-złotnickiej oraz osada ze środkowego okresu lateńskiego i wczesnego okresu wpływów rzymskich w Podłężu (stan. 17), pow. Wieliczka, w świetle badań w latach 2003-2004. W: Z. Bukowski, M. Gerlach (red.), Raport 2003-2004, t. 2, Wstęne wyniki konserwatorskich badań archeologicznych $w$ strefie budowy autostrad w Polsce za lata 2003-2004. Warszawa: Ośrodek Ochrony Dziedzictwa Archeologicznego, s. 638-676.

Fogel J.

1985 Przemiany osadnictwa mikroregionu bnińskiego w epoce brązu i wczesnych okresach epoki żelaza. W: J. Żak, J. Fogel (red.), Materiały do studiów nad osadnictwem bnińskim. Mikroregion bniński (s. 35-118). Poznań: Państwowe Wydawnictwo Naukowe.

Gediga B.

1976a Grody ludności kultury tużyckiej we Wrocławiu-Osobowicach. Wrocław: Zakład Narodowy im. Ossolińskich, Wydawnictwo Polskiej Akademii Nauk.

Gediga B.

1976b Śladami religii Prasłowian. Wrocław: Zakład Narodowy im. Ossolińskich, Wydawnictwo Polskiej Akademii Nauk.

Gediga B.

1979 Zagadnienia religii. W: J. Dąbrowski, Z. Rajewski (red.), Prahistoria ziem polskich, t. 4: Od środkowej epoki brązu do środkowego okresu lateńskiego (s. 320-341). Wrocław: Zakład Narodowy im. Ossolińskich, Wydawnictwo Polskiej Akademii Nauk.

Gediga B., Piotrowska D. (red.).

2000 Kultura symboliczna kręgu pól popielnicowych epoki brąu i wczesnej epoki żelaza w Europie środkowej. Warszawa-Wrocław-Biskupin: Polska Akademia Nauk - Oddział 
we Wrocławiu, Muzeum w Biskupinie - Oddział Państwowego Muzeum Archeologicznego w Warszawie.

Głogowski Z., Szamałek K., Ignaczak M.

2004 Osadnictwo społeczeństw kultur cyklu łużyckiego w strefie nadnotecko-nadgoplańskiej. W: J. Bednarczyk, L. Czerniak, A. Kośko (red.), Archeologiczne badania ratownicze wzdluz trasy gazociagu tranzytowego, t. 3: Kujawy, cz. 5: Osadnictwo społeczeństw kultur cyklu tużyckiego (s. 203-334). Poznań: Wydawnictwo Poznańskie.

Hadaczek K.

1914 Osada przemysłowa w Koszyłowicach z epoki eneolitu. Studya do początków cywilizacji w połud.-wschod. Europie. Archiwum Naukowe, 7(2), Lwów.

Harding A., Ostoja-Zagórski J., Palmer C., Rackham J.

2004 Sobiejuchy: a fortified site of the Early Iron Age in Poland. Polskie Badania Archeologiczne, t. 35. Warszawa: Wydawnictwo Instytutu Archeologii i Etnologii Polskiej Akademii Nauk.

Jacobi G.

1974 Werkzeug und Garät aus dem Oppidum von Manching. Die Ausgrabungen in Manching, 5. Stuttgart: Franz Steiner.

Kaczmarek M.

2002 Zachodniowielkopolskie społeczności kultury tużyckiej w epoce brazu. Poznań: Wydawnictwo Naukowe Uniwersytetu im. Adama Mickiewicza w Poznaniu.

Kendelewicz T.

2006 Sprawozdanie z badań wykopaliskowych stanowiska Wierzchowice 2, pow. Jawor. W:

Z. Bukowski, M. Gerlach (red.), Raport 2003-2004. Wstępne wyniki konserwatorskich badań archeologicznych $w$ strefie budowy autostrad w Polsce za lata 2003-2004 (t. 1, s. 317-328). Warszawa: Ośrodek Ochrony Dziedzictwa Archeologicznego.

Kołacz M.

1995 Osada kultury przeworskiej w Izdebnie Kościelnym, stanowisko I, gmina Grodzisk Mazowiecki. Barbaricum, 5, s. 5-63.

Kołosówna Z.

1950 Przedmioty kultu i zabawki z grodu kultury łużyckiej w Biskupinie. W: J. Kostrzewski (red.), III Sprawozdanie z prac wykopaliskowych w grodzie kultury tużyckiej w Biskupinie w powiecie żnińskim za lata 1938-1939 i 1946-1948 (s. 193-238). Poznań: Polskie Towarzystwo Prehistoryczne.

Krzyszowski A.

2008 Osada ludności kultury łużyckiej na stanowisku 278 (AUT 191) Poznań-Nowe Miasto.

W: H. Machajewski, R. Pietrzak (red.), Archeostrada. Studia i materiaty z badań wykopaliskowych na autostradzie A2 - odcinek wielkopolski, t. 2, Poznań-Nowe Miasto. Źródła archeologiczne do studiów nad pradziejami $i$ wczesnym średniowieczem dorzecza środkowej Warty (s. 49-92). Poznań: Wydawnictwo Poznańskie.

Makiewicz T., Prinke A.

1980 Teoretyczne możliwości identyfikacji miejsc sakralnych. Przegląd Archeologiczny, 28, s. $57-84$.

Malinowski T.

2006 Komorowo, stanowisko 1: Grodzisko kultury tużyckiej - faktoria na szlaku bursztynowym. Rzeszów: Wydawnictwo Mitel.

Marcinkian A.

1972 Cmentarzysko ludności kultury łużyckiej z III-IV okresu epoki brązu w Przyborowie, pow. Nowa Sól. Zielonogórskie Zeszyty Muzealne, 3, s. 173-423. 
Masojć M., Paruzel P.

2006 Badania wykopaliskowe przeprowadzone w latach 2002-2004 na stanowisku $20 \mathrm{w} \mathrm{Bu}$ dziszowie Wielkim, gm. Wądroże Wielkie, woj. dolnośląskie. W: Z. Bukowski, M. Gerlach (red.), Raport 2003-2004. Wstępne wyniki konserwatorskich badań archeologicznych $w$ strefie budowy autostrad w Polsce za lata 2003-2004 (t. 1, s. 245-256). Warszawa: Ośrodek Ochrony Dziedzictwa Archeologicznego.

Mierzwiński A.

2003 Znaki utrwalone $w$ glinie. Społeczno-obrzędowe aspekty działań wytwórczych końca epoki brąu i wczesnej epoki żelaza. Model nadodrzański. Wrocław: Instytut Archeologii i Etnologii PAN.

Meduna J.

1980 Die latènezeitlichen Siedlung in Mähren. Praha: Praha Academia.

Mogielnicka-Urban M.

1984 Warsztat ceramiczny w kulturze łużyckiej. Wrocław: Zakład Narodowy im. Ossolińskich,

Muzolf B. Wydawnictwo Polskiej Akademii Nauk.

1999 Badania archeologiczne wielokulturowego stanowiska w miejscowości Kobielice, stan. 1 (nr GAZ - 119), gm. Zakrzew, woj. pomorsko-kujawskie. [Maszynopis w Europol Gaz S.A. w Warszawie].

Muzolf B.

2002 Wyniki ratowniczych badań wykopaliskowych na terenie odkrywki „Szczerców” KWB „Bełchatów” S.A. na stanowisku nr 12 w Grabku, gm. Szczerców, woj. łódzkie. Kompleks osadniczy z okresów halsztackiego i lateńskiego. W: R. Grygiel (red.), Badania archeologiczne na terenie odkrywki „Szczerców” Kopalni Węgla Brunatnego „Betchatów” S.A. (t. 2, nr 5, s. 121-384). Łódź: Wydawnictwo Fundacji Badań Archeologicznych im. Profesora Konrada Jażdżewskiego.

Ostoja-Zagórski J.

1996 Ornament i plastyka figuralna - sztuka pradziejowa czy przetworzona magia. W: J. Chochorowski (red.), Problemy epoki brązu i wczesnej epoki żelaza w Europie Środkowej. Księga jubileuszowa poświęcona Markowi Gedlowi (s. 415-422). Kraków: Oficyna Cracovia.

Pazda S., Konczewska M., Konczewski P.

2006 Wyniki ratowniczych badań wykopaliskowych na stanowiskach 3 i 4 w Nowej Wsi, gm. Bolesławiec, woj. dolnośląskie. W: Z. Bukowski i M. Gerlach (red.), Raport 20032004. Wstęne wyniki konserwatorskich badań archeologicznych $w$ strefie budowy autostrad w Polsce za lata 2003-2004 (t. 1, s. 291-306). Warszawa: Ośrodek Ochrony Dziedzictwa Archeologicznego.

Podborský V.

1965 Die Hallstattsiedlung in Těšetice. Fontes Archaeologici Pragenses, 9.

Prochnowicz R.J.

1999 Krążki ze skorup naczyń na terenie kultury przeworskiej. W: J. Andrzejowski (red.), COMHLAN. Studia z archeologii okresu przedrzymskiego i rzymskiego w Europie Środkowej dedykowane Teresie Dąbrowskiej w 65. rocznice urodzin (s. 307-318). Warszawa: Fundacja Przyjaciół Instytutu Archeologii Uniwersytetu Warszawskiego.

Słupecki L.P.

1992 Ślęża, Radunia, Wieżyca. Miejsca kultu pogańskiego Słowian w średniowieczu. Kwartalnik Historyczny, 2, s. 3-15. 
Wieczorowski T.

1938 Rzadsze wyroby gliniane (sita, zabawki, przybory tkackie i odlewnicze). W: J. Kostrzewski (red.), Gród prastowiański w Biskupinie w powiecie żnińskim. Sprawozdanie $z$ prac wykopaliskowych $w$ latach 1936-1937 z uwzględnieniem lat 1934-1935 (s. 33-38). Poznań.

Woźniak Z.

1980 Młodsza faza kultury lateńskiej (celtyckiej) i grupa tyniecka. W: J. Wielowiejski, Prahistoria Ziem Polskich, t. V, Późny okres lateński i okres rzymski (s. 248-262). Wrocław: Zakład Narodowy im. Ossolińskich, Wydawnictwo Polskiej Akademii Nauk.

Woźniak Z.

1990 Osada grupy tynieckiej w Podtężu, woj. krakowskie. Wrocław: Zakład Narodowy im. Ossolińskich, Wydawnictwo Polskiej Akademii Nauk.

\title{
FUNCTION OF THE LUSATIAN CLAY DISCS IN THE LIGHT OF NEW FINDS FROM WIELKOPOLSKA
}

\author{
Su m mary
}

Clay discs made of fragments of vessels, parts of bottoms or middle parts of a body, have been found in small numbers at the sites dating to I EB or those associated with the Pomorska or Cloche Grave cultures. They have been more abundant at the Przeworsk culture sites, dating back to the pre-Roman and Roman Iron Age. Within the Lusatian circle, the discs, besides a great assemblage from a stronghold in Biskupin, Żnin county (over 100 pieces), have been known from several sites, mainly settlements, while a few have been recorded within cemeteries. Recently, a collection has been enriched by the artefacts from Beznazwa, Turek county, and Krerów, Poznań county. Except for the find from the grave dating back to III/IV EB, their chronology closes within the period from $\mathrm{V} \mathrm{EB} / \mathrm{Ha} \mathrm{C}$ to $\mathrm{Ha} \mathrm{D}$. Unfortunately, no other areas of their concentration might be indicated outside Kujawy, where the greatest amount of them has been observed, although only at two sites. They have been found in the north-eastern Poland, in Dolny Śląsk (Lower Silesia), in Małopolska (Lesser Poland), as well as in Wielkoplska (Greater Poland).

There are several ideas concerning the function of clay discs - they might have been children's toys or objects associated with the cult of the Sun, although they might have had a purely utilitarian function, and then they would have been used as spindle whorls, polishing stones in pottery workshops or miniature pads used in casting forms. In case of the artefacts discovered at the Lusatian sites any hypothesis seems possible, however that of using the discs as spindle whorls should be discarded as diameters of their holes seem too small. On the other hand, they might have served as toys or polishing stones in pottery workshops. However, the most reliable concept concerning the function of clay discs seems the one interpreting them as miniature pads employed in casting forms used in lost-wax process, especially since a clear chronological and spatial convergence has been noted of decaying moulds and other remnants of metallurgical activity (e.g. funnels, crucibles, casting spoons) and clay discs which thus should be seen as an extension of a tool base associated with a metallurgical process, which is also evidence of the widespread practice of 
bronze casting within the Oder and Vistula basins. However, such a purely utilitarian definition of the function of the discs does not exclude any concepts of their symbolic use. After all, metallurgical process is related to operating with fire, which in many prehistoric and ancient cultures was treated as the earthly representative of the Sun - a symbol of infinity, energy and life force. In this context, a metallurgical act might undoubtedly have a magic meaning.

Translated by Lucyna Leśniak 